\title{
Biossinalização do câncer de tireoide
}

Thyroid cancer bios signaling

Señalización del bios del cáncer de tiroides

Recebido: 06/02/2022 | Revisado: 12/02/2022 |Aceito: 19/02/2022 | Publicado: 01/03/2022

\author{
Amanda Carvalho Garcia \\ ORCID: https://orcid.org/0000-0003-2314-5774 \\ Universidade Federal do Paraná, Brasil \\ E-mail: amanda.ufpr@gmail.com \\ Teresa Cristina Cavalcanti \\ ORCID: https://orcid.org/0000-0002-8555-6547 \\ Universidade Federal do Paraná, Brasil \\ E-mail: tecava@yahoo.com.br \\ Luiz Martins Collaço \\ ORCID: https://orcid.org/0000-0002-3215-1650 \\ Universidade Federal do Paraná, Brasil \\ E-mail:1mcollaco@uol.com.br \\ Hans Graf \\ ORCID: https://orcid.org/0000-0001-8671-1556 \\ Universidade Federal do Paraná, Brasil \\ E-mail: hansgraf@bighost.com.br
}

\begin{abstract}
Resumo
Câncer de tireoide integra subtipos que estão envolvidos em vias sinalização que resultam nas atividades biológicas, como diferenciação, proliferação, na ausência de doença e sobrevida celular. O BRAF é um gene que codifica a proteína quinaseltreonina que integra a via de sinalização MAPKIERK, pois sinais RAF são ativados pela quinase MAPKIERK e ativa ERK।receptores. Na revisão integrativa atual aborda os conceitos dos mecanismos da biossinalização envolvidos no cancer de tireoide. A metologia utilizada fundamentou-se em revisar os princípios contextuais da sinalização que ocorre nos tipos de câncer de tireoide, como os fatores epidemiológicos, etiológicos e fisiológicos. Esta revisão integrativa da literatura objetiva atualizar e mostrar a importância da compreensão sobre a biossinalização do câncer de tireoide, que visa destacar o papel dos genes envolvidos em cada tipo de neoplasia maligna da tireoide. estudos proporcionam o engajamento criação de paneis de perfil de mutação genética, que evidencia fatores científicos que ajudem na compreensão da complexidade etiológica do câncer de tireoide.
\end{abstract}

Palavra-chave: Sinalização; Câncer; Tireoide; MAPK; BRAF.

\section{Abstract}

Thyroid cancer integrates subtypes that are involved in signaling pathways that result in biological activities, such as differentiation, proliferation, in the absence of disease, and cell survival. BRAF is a gene that encodes the protein kinaselthreonine that integrates the MAPKIERK signaling pathway, as RAF signals are activated by the MAPKIERK kinase and activates ERKlreceptors. The current integrative review addresses the concepts of biosignaling mechanisms involved in thyroid cancer. The methodology used was based on reviewing the contextual principles of signaling that occurs in types of thyroid cancer, such as epidemiological, etiological and physiological factors. This integrative literature review aims to update and show the importance of understanding the biosignaling of thyroid cancer, which aims to highlight the role of genes involved in each type of malignant thyroid neoplasm. studies provide the engagement creation of genetic mutation profile panels, which evidence scientific factors that help in understanding the etiological complexity of thyroid cancer.

Keywords: Signalization; Cancer; Thyroid; MAPK; BRAF.

\section{Resumen}

El cáncer de tiroides integra subtipos que están involucrados en vías de señalización que dan como resultado actividades biológicas, como diferenciación, proliferación, en ausencia de enfermedad y supervivencia celular. BRAF es un gen que codifica la proteína quinasaltreonina que integra la vía de señalización MAPKIERK, ya que las señales RAF son activadas por la quinasa MAPKIERK y activa los receptores ERK. La revisión integradora actual aborda los conceptos de los mecanismos de bioseñalización involucrados en el cáncer de tiroides. La metodología utilizada se basó en revisar los principios contextuales de señalización que se dan en los tipos de cáncer de tiroides, como son los factores epidemiológicos, etiológicos y fisiológicos. Esta revisión integrativa de la literatura tiene como objetivo actualizar y mostrar la importancia de comprender la bioseñalización del cáncer de tiroides, que tiene como objetivo resaltar el papel de los genes involucrados en cada tipo de neoplasia maligna de tiroides. Los estudios brindan la participación en la 
creación de paneles de perfiles de mutaciones genéticas, que evidencian factores científicos que ayudan a comprender la complejidad etiológica del cáncer de tiroides.

Palabras clave: Señalización; Cáncer; Tiroides; MAPK; BRAF.

\section{Introdução}

O carcinoma de tireoide origina-se de única célula alterada por lesões dos genes que controlam a proliferação celular, podendo ser atribuídas características a células do parênquima tireoidiano (Hegedus, 2004). O câncer de tireoide é o $5^{\circ}$ câncer mais prevalente em mulheres americanas dos Estados Unidos, pois a sua incidência entre 1\% a 4\% em relação as demais neoplasias malignas (Siegel et al., 2015; Haroon et al., 2019).

Segundo dados divulgados pelo Instituto Nacional do Cancer (INCA), o carcinoma papilífero de tireoide entre 50\% e $80 \%$ dos casos, algo visto em comparação aos casos de carcinoma folicular que se estima $15 \%$ a $20 \%$ dos casos e o de células de Hürthle, além disso, os carcinomas pouco diferenciados ou indiferenciados representam cerca de $10 \%$ dos casos (INCA, 2022).

As células foliculares originam o câncer diferenciado de tireoide (CDT) e as células parafoliculares ou C que gera o carcinoma medular de tireoide (CMT) (Colin et al., 2013; Noone et al., 2017). Já os carcinomas diferenciados da tireoide (CDT) integra as neoplasias papilar e folicular: carcinoma papilífero da tireoide (PTC), o carcinoma folicular da tireoide (FTC), e o carcinoma de células de Hurtlhe cuja prevalência de 90 a 95\% das neoplasias malignas de tireoide (Lee et al., 2021).

O carcinoma medular da tireoide (CMT) é responsável por 3\% a 5\% de todas as neoplasias malignas da tireoide (Cote et al., 2015; Hou, He e Chute, 2020). Na maioria dos casos de carcinomas anaplásicos são considerados mais agressivos e mais resistentes ao tratamento, ao contrário dos diferenciados e medulares que aderem com certa facilidade ao tratamento, conforme o comportamento do tumor. O carcinoma de tireoide possui uma incidência a cerca de 3\% no mundo e o carcinoma anaplásico da tireoide é responsável por menos de 1\% de todos os cânceres de tireoide (Gallardo et al., 2020).

O carcinoma da tireoide sendo o papilífero e o folicular originados pelo epitélio folícular, que apresentam células epiteilias cuboides dispostas em camada única e secretam coloide nos interior dos folículos conforme ação do hormonio tireoidiano (Lee et al., 2022). Quando ocorre a perda da diferenciação celular, o tumor torna-se menos diferenciado e isso resulta na maior agressevidade, o que dificulta a terapia convencional e prognóstico (Lee et al., 2022).

Nos casos de carcinomas diferenciados da tireoide (CDT) quando progride para desdiferenciação celular, sendo o carcinoma diferenciado (insular) ou iniferenciado (anaplásico), resulta num imenso desafio de segmento terapeutico (Wiseman et al., 2003 a, b; Landa et al., 2016).

Nesta revisão bibliográfica abordou-se um levamento sobre os conceitos dos mecanismos da biossinalização envolvidos no cancer de tireoide.

\section{Metodologia}

Para a elaboração do estudo a metodologia empregada fundamentou-se em revisar os princípios contextuais da sinalização que ocorre nos tipos de câncer de tireoide, como os fatores epidemiológicos, etiológicos e fisiológicos. Esta revisão integrativa da literatura objetiva atualizar e mostrar a importância da compreensão sobre a biossinalização do câncer de tireoide, que visa destacar o papel dos genes envolvidos em cada tipo de neoplasia maligna da tireoide. O presente trabalho é uma revisão de literatura, na qual foi realizada uma busca bibliográfica nas bases de dados Publicações Médicas (PubMed) e Biblioteca Virtual em Saúde (BVS) que relatavam os temas propostos de 2000 a 2022. Os descritores elegíveis utilizados foram: "câncer de tireoide", "vias de sinalização" e "genes". Os critérios de inclusão foram artigos que abordassem o tema da presente revisão de literatura, sem restrição de idioma, artigos de estudo in vitro, in vivo, relato de caso, revisão de literatura e livros cuja literatura proveria melhores evidências para este trabalho. Primeiramente, foram selecionados de acordo com os títulos dos trabalhos e 
posteriormente analisados os resumos. Trabalhos que não apresentaram metodologia detalhada no resumo ou não correspondessem ao tema proposto foram excluídos, dessa forma, 48 artigos que se enquadravam na proposta do tema, para leitura na integra.

\section{Resultados e discussão}

\subsection{Fatores estimulantes da proliferação celular tireoidiana}

Os fatores de risco avaliados baseiam-se e dados clínicos e anatomopatológicos que em análises multivariadas, que revelam sua independência pelo prognóstico da doença (Lania et al., 2006; Lim et al., 2017). Os tumores considerados benignos eventualmente podem apresentar um comportamento mais agressivo (Zaballos e Santisteban, 2017). Para isso, estudos moleculares que buscam a identificação de genes expressos na adesão e disseminação celular, a expressão de oncogenes e antioncogenes (Wiseman et al., 2003 a, b; Landa et al., 2016).

O hormônio tireotrófico da hipófise (TSH), o fator de crescimento epidérmico (EGF), o fator de crescimento transformmacielador (TGF- $\alpha$ ) e fator de crescimento semelhantes a insulina (IGF) Como também, fator de crescimento fibroblasto (BFGF), gonadotropina coriônica humana (hCG), hormônio de crescimento (GH) e o hormônio de crescimento do hepatócito (HGF) (Kimura, Matsuo e Ricarte-Filho, 2007). Esses fatores podem codificar receptores específicos na célula, que uma vez ativados modificam e transmitem o sinal a outras partes da célula através de diversas vias de transdução, como da adenilciclase, proteinoquinase, tirosina-quinase e cascata da fosfolipase C (Hoogen et al., 2018).

As proteínas normais codificadas pelos genes estimuladores atuam na membrana celular, no citoplasma e no núcleo. Onde a ação de receptores de fatoriais, tais como, proteínas envolvidas na transmissão de sinais dentro das células (mensageiros secundários), bem como proteínas reguladoras nucleares. Os oncogenes promovem o crescimento celular autônomo nas células cancerosas e suas contrapartes celulares não mutadas (proto-oncogenes) (Kopnin, 2000; Gerdes, 2002). Os oncogenes são originados através da mutação nos proto-oncogenes, caraterizadas pelo crescimento celular na ausência de sinais promotores de crescimento normais, originando produtos oncoproteínas (Nikiforov, 2008; Nikiforov et al., 2011; Yi et al., 2017).

A proliferação celular fisiológica ocorre: 1. Ligação de um fator de crescimento ao seu receptor específico; 2. Ativação transitória e limitada do receptor do fator de crescimento, o qual ativa diversas proteínas transdutoras de sinal no folheto interno da membrana plasmática; 3. Transmissão de sinal através do citosol para o núcleo por meio dos segundos mensageiros, ou pela cascata de moléculas transdutoras de sinal; 4. Indução e ativação dos fatores nucleares, reguladores que iniciam a transcrição do DNA; 5. Entrada e progressão da célula no ciclo celular, resulta na divisão celular (Nikiforov, 2008).

Os proto-oncogenes agem no controle do crescimento celular, onde mutações, rearranjos estruturais ou amplificação genéticas, podem provocar a perda do poder regulador da proliferação celular, resultando na desordem do crescimento celular (Nikiforov, 2008; Nikiforov, Nikiforova, 2011; Yi et al., 2017). Apenas um alelo do gene estimulado é suficiente para a formação do oncogene. Os genes supressores perdem seu poder inibidor, ocasionando na inativação de dois alelos (antioncogenes) (Kopnin, 2000; Gerdes, 2002).

As três classes de oncogenes uma vez ativadas na iniciação e progressão dos tumores tireoidianos, são eles: proteína $\mathrm{G}$ (liga ao GTP), receptores de tirosina-quinase e proteínas nucleares (Figura 1). 
Figura 1 - Transdutores de sinal: A) receptor associado a proteína G, ocorre a interação do ligante externo (S) extracelular ao receptor $(\mathrm{R})$, que ativa a proteína intracelular ligante de GTP $(\mathrm{G})$, que regulada por uma enzima, o que resulta num segundo mensageiro. B) receptor tirosina-quinase a ligante ativa atividade tirosina-quinase através da autofosforilação. C) receptor guanilil-ciclase ocorre a interação do ligante (S) com o domínio extracelular resultando num segundo mensageiro intracelular uma guanosina trifosfato (GTP) para monofosfato cíclico de guanosina (cGMP). D) receptor nuclear ligantes específicos (S), como hormônios estrogênio, altera a expressão de genes específicos. E) canal iônico na membrana plasmática possui comportas que abrem e se fecham, em resposta a interação do ligante $(\mathrm{S})$ ou pelo potencial de membrana. F) receptor de adesão a molécula liga-se na matriz extracelular resultando na mudança da conformação do citoesqueleto.

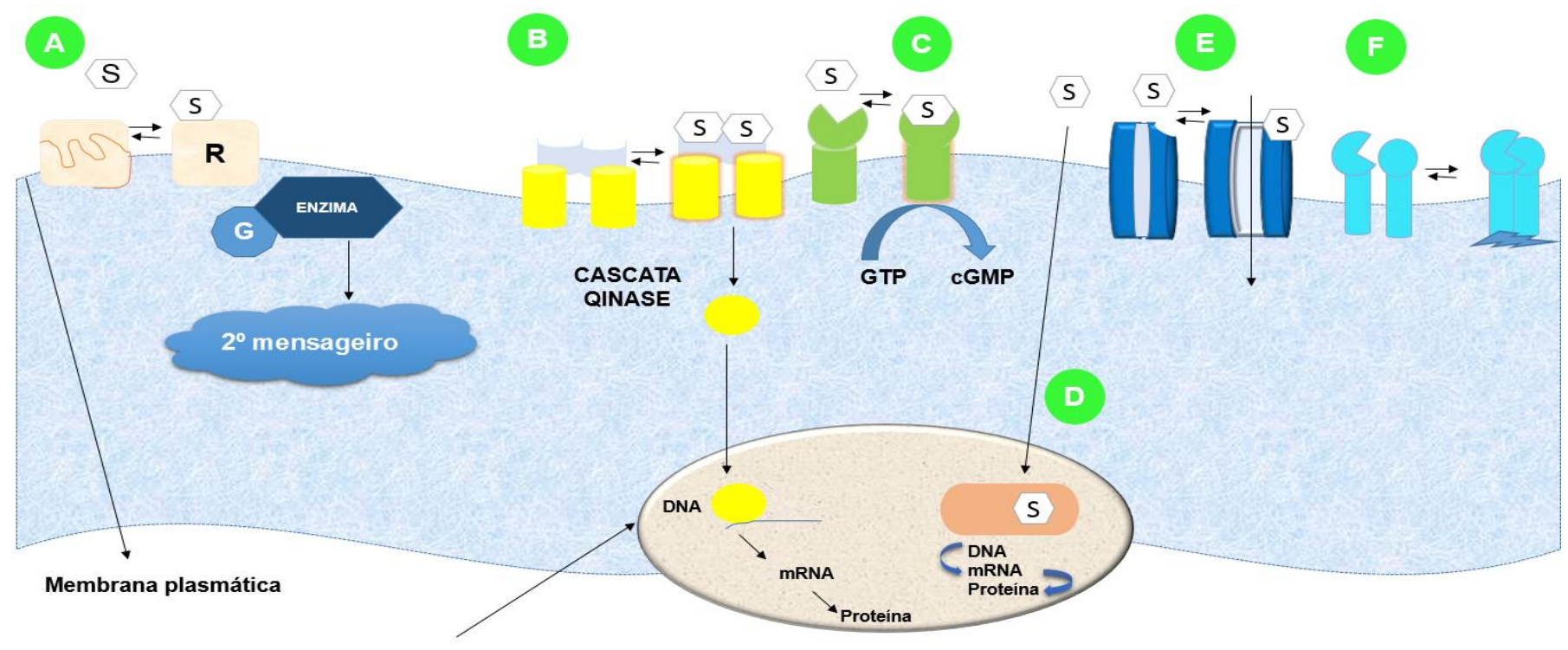

Envelope nuclear

Fonte: Autores (2022).

\section{Receptores Associadas a Proteína G}

A Ras integra a família de proteínas $G$ pequenas que se ligam a nucleotídeos permeiam várias transduções de sinal, como por exemplo, a regulação da expressão genica pela insulina através da cascata de MAP-quinases (Afzal, 2020). Os oncogenes ras é uma classe que pertencente à família (H-ras, N-ras, K-ras) proteínas de alto peso molecular. As mutações ocorrem nos códons 12, 13 e 61, são encontrados em vários tipos de tumores tireoidianos, benignos ou malignos e em lesões hiperplásicas não neoplásicas (Zaballos e Santisteban, 2017).

O gene RAS possui um papel importante nas cascatas de sinalização posteriores aos receptores de fatores de crescimento, via de sinalização MAPK, a via AKT e a via RAL GDS (Zaballos et al., 2017). As mutações no RAS representam 40 a 50\% de prevalência dos casos carcinoma folicular de tireoide (Lee et al., 2021).

As proteínas RAS dependem de duas reações, sendo a primeira a troca de nucleotídeos (GDP por GTP) que ativa a proteína RAS, proporcionando a fosforilação processo pelo qual ocorre a adição de um grupo fosfato na guanosina difosfato, sendo este tornar-se a proteína hidrofóbica apolar e hidrofílica polar. E a hidrólise de GTP que converte RAS ativa, ligada ao GTP, em sua forma inativa, ligada GDP, esses processos são regulados extrinsecamente por outras proteínas (Shaul et al., 2007; Bos et al., 2007; Zaballos eet al., 2017). As proteínas normais são catabolizadas pelas proteínas ativadoras da GTPase (GAP), ligam-se ao RAS ativa que aumentam atividade de GTPase em 1.000 vezes levando ao término da tradução de sinal. O GAP funciona como 
freios que controlam a atividade da RAS (Zaballos e Santisteban, 2017). Onde a RAS mutada fica aprisionada em sua forma ativada de ligação GTP e a célula é forçada a ficar em um estado continuamente ativado de proliferação (Figura 2).

Figura 2 - Ativação e inativação da proteína Ras. 1) Proteínas Ras Ativa - quando proteína Ras é ativada pela GTPase (GAPs) resultando na fosforilação (adição de grupo fosfato) da GTP (guanosina trisfosfato), e na ativação da via da MAP-quinase que ativa a proliferação celular. 2) Proteínas Ras Inativa - quando ocorre a hidrólise de um grupo fosfato do GTP pela ação da GTPases retornando ao estado GDP (guanosina difosfato). A inibição da hidrólise do GTP ocorre a mutação RAS ativando a proliferação anormal.

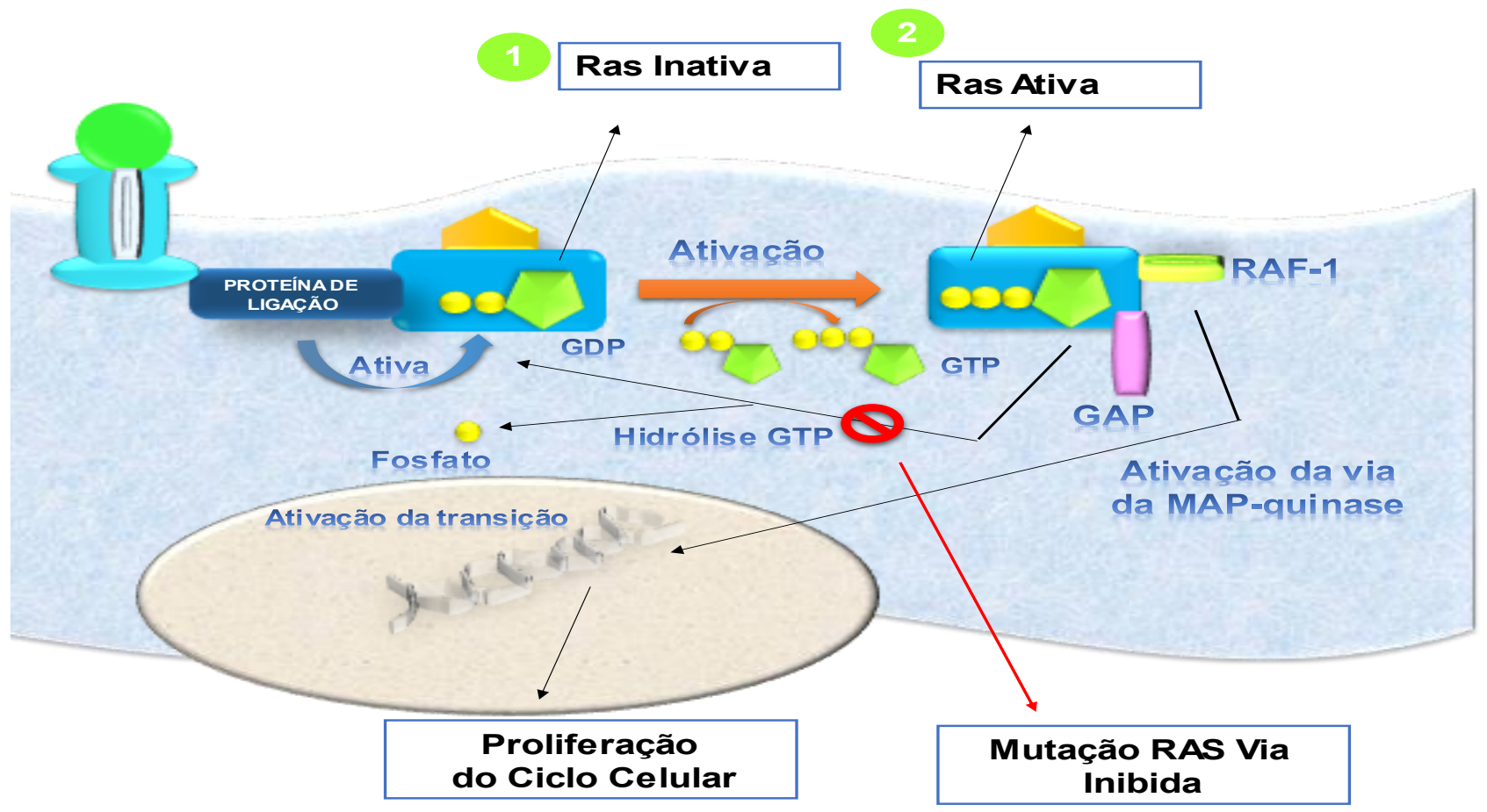

Fonte: Autores (2022).

\section{Carcinoma Papilar}

Em cada variante de carcinomas tireoidianos há variações genéticas. Em carcinoma tireoidiano papilar (PTC), a via de sinalização MAP-quinase é a principal na célula folicular tireoidiana que responde por estímulos de diferentes fatores de crescimento ou alteração constituída do gene RET, o qual ativa a cascata RAF\RAS RET (Abdullah et al., 2019; Li et al., 2019). A ativação de efetores ao longo da via de sinalização MAPK, está relacionada a transformação maligna da tireoide (NIKIFOROV, 2008). A mutações pontuais ativadoras em BRAF representam $45 \%$ das alterações genéticas mais frequentes, em seguida de $20 \%$ do rearranjo do gene RETIPTC (rearranjed in transformation yapilary thyroid carcinoma), caracterizam a maioria dos carcinomas papilares (Hussain et al., 2015; Bautista, Knippler e Ringel, 2021). Já a ativação do gene RAS em PCT é menos frequente, em relação aos carcinomas foliculares, que apresentam prevalência das mutações RAS e na via de sinalização PI-3K\AKT (Figura 3). 
Figura 3 - 1) Carcinoma papilar podendo ocorrer a translocação ou inversão. 2) ocorre mutações pontuais em carcinoma folicular e anaplásico. 3) ocorre mutações pontuais em carcinoma papilar. 4) ocorre translocações em carcinoma folicular. 5) ocorre mutações pontuais e amplificações em carcinoma folicular e anaplásico. 6) ocorre mutações pontuais em carcinoma folicular e anaplásico. Essas alterações genéticas resultam no crescimento, na proliferação e diferenciação celular.

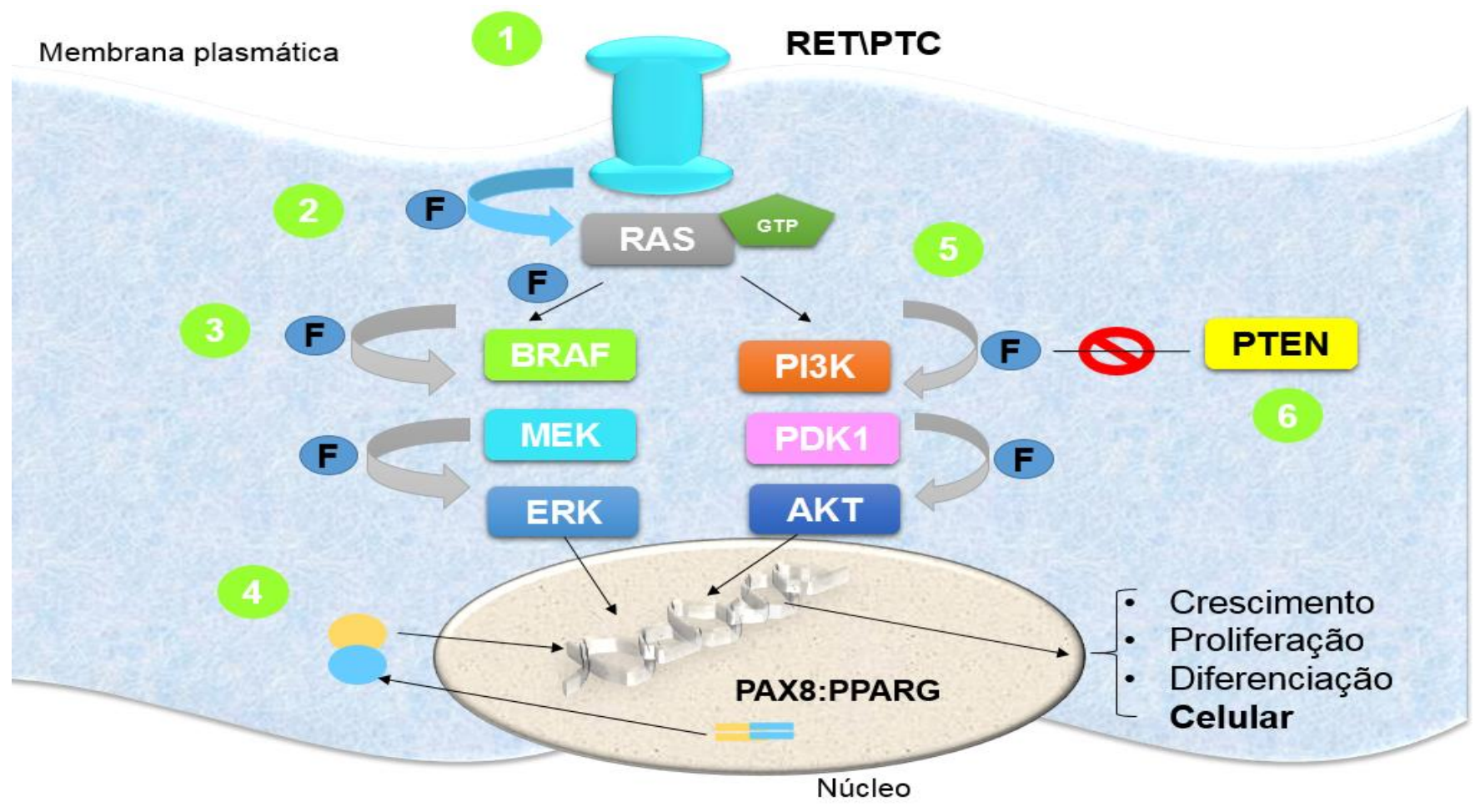

Fonte: Autores (2022).

O rearranjo RET $\backslash P T C$, a proteína codificada pelo gene RET, é um receptor transmembrana da família tirosina-quinase (Fusco et al., 1987). O gene RET possui 21 exons, localizado na posição cromossômica 10q11-2, a proteína RET glicosilada 170 kDa é composta por 3 domínios: a primeira é domínio extracelular com uma região distal caderina-like na $4^{\circ}$ posição, possui uma região justa de membrana rica em cisteína, um domínio transmembrana hidrofóbica e a terceira é o domínio intracelular de atividade tirosina-quinase C (Maciel, 2002).

O proto-oncogene RET está envolvido na regulação do crescimento, na diferença e na migração de células de origem da crista neural. Os ligantes glial cell-line derival neutrophilic fator (GDNF) pertence a superfamília TGF $\beta$, expressos a fusão do proto-oncogene RET (Maciel 2002; (Zaballos e Santisteban, 2017). A proteína oncogênica RET\PTC apresenta domínio Nterminal doada por um dos segmentos gênicos, que confere ao oncogene a propriedade de oligomerização, com a porção Cterminal do receptor tirosina-quinase RET, que perde os domínios extracelular e transmembrana, porém, retém a função tirosinaquinase do receptor, mantendo a ativação constitutiva da cascata de sinalização MAP-quinase intracelular. O rearranjo RET $\backslash P T C 1$ e RET\PTC3 são os mais observados em PTC, porém outras recombinações genéticas já foram descritas (Nikiforov, 2008; Lin e al., 2010; Zaballos e Santisteban, 2017).

Após a ligação ao receptor RET desencadeia a dimerização, o qual ativa a atividade quinase do receptor, ocorrendo a autofosforilação de resíduos de tirosinas dando início a sinalização intracelular, pela interação de efetores específicos nos locais de tirosinas fosforiladas (Nikiforov, 2008; Cantara et al., 2010).

O gene RET é expresso em células de linhagem neural, células C da tireoide e na medula adrenal, porém, não há expressão em células epitelial de tireoide normal. Em carcinoma medular de tireoide há alta prevalência da mutação no gene RET. O rearranjo do gene RET no PTC, origina-se da inversão intracromossômica ou da translocação intercromossômica, o que resulta 
no rearranjo RET\PTC1 (Fusco et al., 1987). Esta translocação de RET\CPT representa 7\% dos casos o que difere da mutação RAS (Cancer Genome Atlas Research Network, 2014; Cancer Genome Atlas Research Network et al., 2013).

$\mathrm{Na}$ inversão paracêntrica do cromossomo 10, permeada pela recombinação ilegítima entre RET e o gene H4 que está 30 megabases distantes (Celetti et al., 2004). Apesar da distância linear ser grande entre eles, a recombinação RET e H4, promovida pelas proximidades no núcleo. O loci RET e H4 no núcleo interfásico pelo menos 1 par com justaposição de RET e H4, representa $35 \%$ nas células tireoidianas humanas normais, $21 \%$ em linfócitos de sangue periférico e $6 \%$ em células epiteliais de mama (Celetti et al., 2004).

A configuração espacial nucelar do RET e H4 é uma base para a geração do rearranjo RET $\backslash$ PTC induzida pela radiação, o que gera a quebra da dupla fita de cada gene envolvido. A radiação ionizante predispõe a carcinogênese da célula folicular tireoidiana, podendo ocorrer o evento RET\PTC, tanto em crianças ou em adultos (Celetti et al., 2004).

A mutação que ocorre no gene BRAF é somática, o que leva ativação constitutiva da reação quinase pela substituição da valina para ácido glutâmico no aminoácido 599 (V599E) (Maciel, Kimura e Cerutti, 2005). Essa mutação ocorre exclusivamente em PTC e tem prevalência seletiva para a forma clássica e a variante de células altas (Hussain et al., 2017). As formas agressivas PTC pouco diferenciados e carcinoma anaplásicos com focos de lesão papilífera tem BRAF ${ }^{\text {V599E }}$ sugere participação de BRAF na progressão de agressividade tumoral (Nikiforov, 2011).

Nos mamíferos apresentam as três isoformas da proteína RAF (ARAF, BRAF e CRAF) são expressos em diferentes tecidos (Robinson e Cobb, 1997). A isoforma CRAF está expressa em todas as células, já a isoforma BRAF está expressa em células hematopoiéticas, sistema nervoso, testículos e com predominância nas células foliculares tireoidianas. A proteína RAF possuem três regiões conservadas: CR1 e CR2 com N-terminal cuja função é regulatória, porque a região RBS da extremidade CR1, é onde ocorre a ligação da proteína RAS, e a extremidade CR3 possui C-terminal de domínio quinase (Figura 4) (Hussain et al., 2015).

Figura 4 - Na mutação BRAF ocorre a substituição do aminoácido valina (V) na posição 600 em cor laranjada, pelo aminoácido o ácido glutâmico (G) em cor esverdeada, configurando a transversão T1999A no nucleotídeo do exon 15.

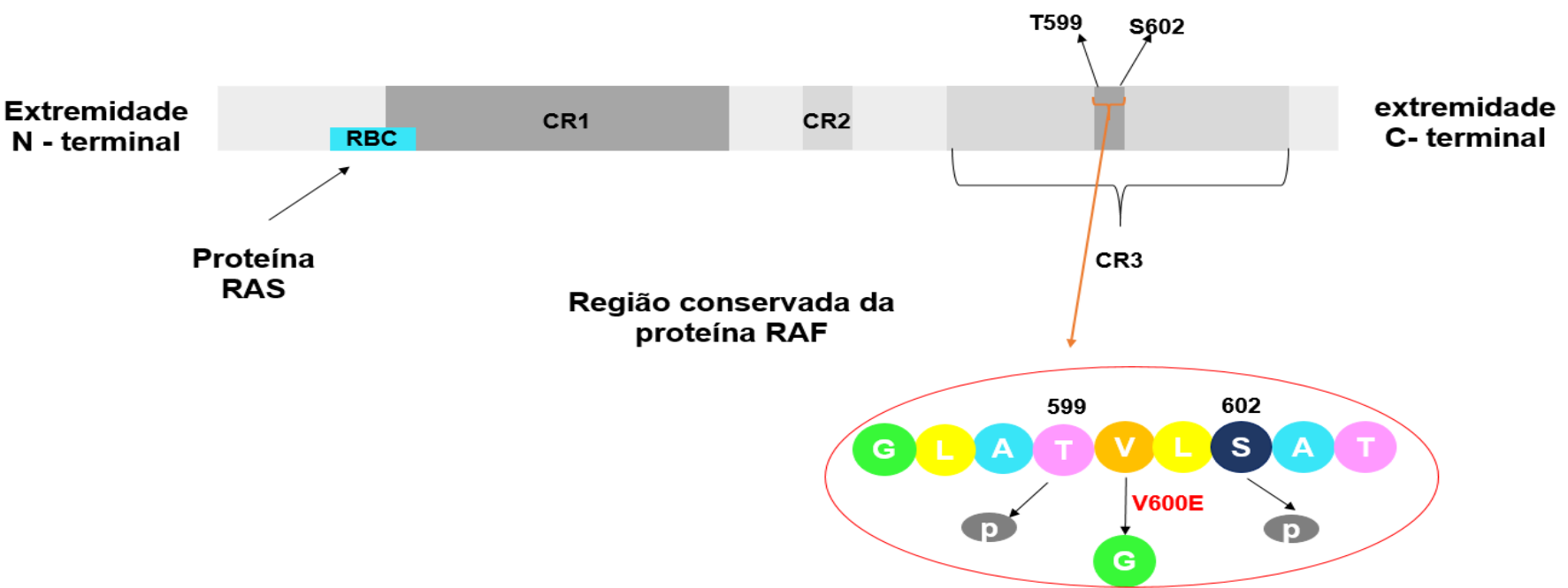

Fonte: Modificado de HUSSAIN et al., (2015).

Isoforma BRAF possui alta afinidade MEK-1 e MEK-2 é mais eficiente na fosforilação de MEK do que nas isoformas RAF (Robinson e Cobb, 1997; Maciel, 2002). A mutação BRAF V599E a troca de aminoácidos ativa a proteína desestabilizando a forma inativa, resultando na fosforilação constitutiva dos aminoácidos adjacentes, propiciando uma capacidade oncogênica. Estudos em in vitro descrevem que a isoforma BRAF com mutação V600E tem atividade quinase basal elevada e sustenta a via 
MAP-quinase e induz a transformação celular (Mitsutake et al., 2005), e não se propõe aos oncogenes RAS ou RET\CPT ( Kimura et al. 2003 , Soares et al. 2003 )

A mutação $\mathrm{BRAF}^{\mathrm{V} 600 \mathrm{E}}$ representa $80 \%$ dos casos de carcinoma papilífero de tireoide (Abdullah et al., 2019). Já nos casos de carcinoma folicular da tireoide e em tumores benignos cuja mutação é ausente em sua maioria, porém a mutação BRAF pode estar presente nos casos de microcarcinomas papilares podendo resultar o início da proliferação tumoral da tireoide (Nikiforova et al. 2003 ).

Algumas mutações pontuais dos genes RAS podem ser encontradas em 30\% dos casos em câncer humano na sua totalidade, como por exemplo, a isoforme NRAS pode ser observado em CFT presente em tumores benignos e malignos (Moura, Covaca e Leite, 2021).

\section{Carcinoma Folicular}

Em carcinomas foliculares ocorre mutações pontuais que ativam a via de sinalização PI-3K\AKT, resultando na ativação do gene RAS e PIK3CA, provocando a inativação do gene supressor de tumor o PTEN, o qual desempenha um papel de regulador negativa nessa via (Zaballos etal., 2017). Cerca de 10\% dos casos de CFT observar-se ativação da PI3K. O aumento das mutações de RAS e PIK3CA favorece a progressão de adenomas foliculares benignos para carcinomas foliculares, como também, para carcinomas anaplásicos, devido a translocação no receptor gama $(\gamma)$ que uma vez ativado via proxissoma PAX8 (PPAR $\gamma)$ cuja prevalência de 30 a 35\% em CFT (Raman et al., 2014; Landa et al. al. 2016).

Mutações somáticas ou deleções em PTEN, são menos frequentes nas em tumores bem diferenciados (Dahia et al. 1997 , Halachmi et al. 1998 , Hsieh et al. 2000), porém, com a evolução molecular pode-se observar que a translocação na 10q23, o que resulta na fusão do gene homeo-box pareado PAX8, cuja importância no desenvolvimento da tireoide, com o gene PPAR $\gamma 1$ que é um receptor ativado por proliferadores de peroxissoma. Essa fusão PAX8:PPAR $\gamma 1$ (peroxissomo proliferatoractived receptor gamma 1) produz um receptor genético nuclear de hormônios onde ativa o crescimento celular, proliferação e diferenciação. Essa translocação atinge cerca de 20 a 60\% dos casos de câncer de tireoide (YEH ET AL., 1999).

O gene supressor de tumor PTEN é uma fosfatase dupla e especifica a qual está relacionada a várias desordens tireoidianas, como o bócio multinodular, adenoma da tireoide e carcinoma. Além disso, mutação na linhagem germinativa do PTEN causadora da síndrome de Cowden, desencadeia a uma desordem de no crescimento de tumores hamartomosas (Lima et al., 2012). Os mecanismos epigenéticos como as alterações na via MAPK que resultam na redução na expressão da proteína e a hipermetilação do promotor PTEN, proporcionando a perda da expressão de PTEN em tumores de tiroide (Alvarez-Nunez et al. 2006).

Por outro lado, a busca pelo conhecimento dos eventos desencadeados pelo gene PTEN em tireoide, gera muita incerteza, pois ainda não está complemente lucidado os mecanismos.

\section{Carcinoma Anaplásicos}

São carcinomas indiferenciados do epitélio folicular tireoidiano, de alta agressividade que perdeu em sua maioria ou totalidade o tecido de origem (Carvalho e Graf, 2005), porque são difíceis de serem diferenciados. As desordens moleculares são oriundas das mutações no gene RAS ou PIK3CA, porém, podem surgir de neoplasias já existentes que possuem fatores genéticos, como a inativação da $p 53$ ou pela ativação da $\beta$-catenina (Saini et al., 2018).

Na maioria dos casos de carcinoma anaplásico de tireoide (CAT) está presente mutações no gene supressor tumoral o p53 cerca de 50\% a 80\% (Hou et al., 2007; Santarpia et al., 2008; Nikiforova et al., 2013). Em relação a mutação RAS é observado cerca de $20 \%$ a $40 \%$ dos casos de CAT (Carling T et al., 2014).

O carcinoma anaplásico de tireoide é podem invadir outros tecidos como gordura, esôfago, traqueia e laringe, mas na fase de metástase atinge os pulmões, ossos e cérebro, representa 70\% dos casos (Saini et al., 2018; Bible et al., 2021). 


\section{Carcinoma Medular}

Nos carcinomas tireoidianos medulares é tumor neuroendócrino, decorrentes das células C que produzem calcitonina (Moura, Covaca e Leite, 2021). Considerado um tumor neuroendócrino raro cerca de 2 a $4 \%$ dos casos de câncer de tireoide, onde observa-se mutações germinativas RET arranjadas o proto-oncogene Transfection (RET) representa 50\% dos casos (Okafor et al., 2021). Além disso, ocorrem em neoplasias endócrinas múltiplas do tipo II (MEN-2), que estão associadas as mutações nas células germinativas do proto-oncogene RET, e não nas translocações RET\PTC que são rearranjos cromossômicas. (Bim et al., 2019). Na maioria das vezes são vistos em canceres tireoidianos medulares esporádicos não familiares cerca de $70 \%$ dos casos (Barletta JA, Nosé V, Sadow, 2021).

As mutações de RET estão envolvidos com as síndromes de neoplasia endócrina múltipla (MEN) tipo 2 MEN2A e MEN2B e carcinoma medular de tireoide familiar (CMFT), sendo que 70 mutações RET estão envolvidos, porém devido a indeterminada relação entre genótipo e fenótipo resultante do amplo leque multivariado das correlações clínicas inseridas nas diferentes famílias que apresentam essa mutação, além de dificultar tomada terapêutica integrada as síndromes (MEN) (Wells et al., 2013; Ceolin et al., 2019). Além disso, pode ocorrer novos rearranjos envolvendo o gene RET em carcinoma papilífero de tireoide CPT (Staubitz et a., 2019).

\section{Considerações Finais}

Estudos que integram as neoplasias de tireoide e a sinalização celular associadas a fatores genéticos, vem ampliando o conhecimento acerca das neoplasias tireoidianas. As vias de sinalização celular envolvem receptores de membrana celular que desencadeando estímulos para o meio extracelular, resultando na ativação ou inativação de uma determinada via. Compreender que os subtipos de canceres de tireoide estão envolvidos em com algum tipo de mutação, sendo somática, germinativa, rearranjo ou translocação, reflete na importância da abordagem do diagnóstico molecular. Assim, esses estudos proporcionam o engajamento criação de paneis de perfil de mutação genética, que evidencia fatores científicos que ajudem na compreensão da complexidade etiológica do câncer de tireoide. Importante ressaltar que o presente estudo apresentou algumas limitações, devido a falta de abrangência de estudos que detalhassem com veemência de amplo detalhe as vias de sinalização do câncer de tireoide,

\section{Agradecimentos}

Os autores agradecem ao Programa de Pós-graduação em Medicina Interna e Ciências da Saúde da Universidade Federal do Paraná e à Coordenação de Aperfeiçoamento de Pessoal de Nível Superior (CAPES) - Código de Finanças 001 e ao Hamashia, J.C pelo apoio total.

\section{Referências}

Abdullah, M. I., Junit, S. M., Ng, K. L., Jayapalan, J. J., Karikalan, B., \& Hashim, O. H. (2019). Papillary Thyroid Cancer: Genetic Alterations and Molecular Biomarker Investigations. International journal of medical sciences, 16(3), 450-460. https://doi.org/10.7150/ijms.29935

Afzal M. S. (2020). G proteins: binary switches in health and disease. Central-European journal of immunology, 45(3), 364-367. https://doi.org/10.5114/ceji.2020.101271

Barletta, JA, Nosé, V., \& Sadow, PM (2021). Genômica e Epigenômica do Carcinoma Medular de Tireóide: Da Doença Esporádica às Manifestações Familiares. Patologia endócrina, 32 (1), 35-43. https://doi.org/10.1007/s12022-021-09664-3.

Bautista, L., Knippler, C. M., \& Ringel, M. D. (2020). p21-Activated Kinases in Thyroid Cancer. Endocrinology, 161(8), bqaa105. https://doi.org/10.1210/endocr/bqaa105.

Bim, LV, Navarro, F., Valente, F., Lima-Junior, JV, Delcelo, R., Dias-da-Silva, MR, Maciel, R., Galante, P., \& Cerutti, JM (2019). Cópias retropostas do gene RET: um evento somaticamente adquirido no carcinoma medular de tireoide. BMC medical genomics, 12 (1), 104. https://doi.org/10.1186/s12920-019-0552-1

Cancer Genome Atlas Research Network (2014). Integrated genomic characterization of papillary thyroid carcinoma. Cell, 159(3), 676-690. https://doi.org/10.1016/j.cell.2014.09.050 
Cancer Genome Atlas Research Network, Weinstein, JN, Collisson, EA, Mills, GB, Shaw, KR, Ozenberger, BA, Ellrott, K., Shmulevich, I., Sander, C., \& Stuart, JM (2013). O projeto de análise Pan-Cancer do Atlas do Genoma do Câncer. Genética da natureza, 45 (10), 1113-1120. https://doi.org/10.1038/ng.2764

Cantara, S., Capezzone, M., Marchisotta, S., Capuano, S., Busonero, G., Toti, P., Di Santo, A., Caruso, G., Carli, A. F., Brilli, L., Montanaro, A., \& Pacini, F. (2010). Impact of proto-oncogene mutation detection in cytological specimens from thyroid nodules improves the diagnostic accuracy of cytology. The Journal of clinical endocrinology and metabolism, 95(3), 1365-1369. https://doi.org/10.1210/jc.2009-2103

Celetti, A., Cerrato, A., Merolla, F., Vitagliano, D., Vecchio, G., \& Grieco, M. (2004). H4(D10S170), um gene frequentemente rearranjado com RET em carcinomas papilares de tireoide: caracterização funcional. Oncogene, 23 (1), 109-121. https://doi.org/10.1038/sj.onc.1206981

Ceolin, L., Duval, M., Benini, AF, Ferreira, CV, \& Maia, AL (2019). Carcinoma medular de tireoide além da cirurgia: avanços, desafios e perspectivas. Câncer endócrino, 26 (9), R499-R518. https://doi.org/10.1530/ERC-18-0574

Cohen, Y., Xing, M., Mambo, E., Guo, Z., Wu, G., Trink, B., Beller, U., Westra, W. H., Ladenson, P. W., \& Sidransky, D. (2003). BRAF mutation in papillary thyroid carcinoma. Journal of the National Cancer Institute, 95(8), 625-627. https://doi.org/10.1093/jnci/95.8.625

Colin, I. M., Denef, J. F., Lengelé, B., Many, M. C., \& Gérard, A. C. (2013). Recent insights into the cell biology of thyroid angiofollicular units. Endocrine reviews, 34(2), 209-238. https://doi.org/10.1210/er.2012-1015

Cote, G. J., Grubbs, E. G., \& Hofmann, M. C. (2015). Thyroid C-Cell Biology and Oncogenic Transformation. Recent results in cancer research. Fortschritte der Krebsforschung. Progres dans les recherches sur le cancer, 204, 1-39. https://doi.org/10.1007/978-3-319-22542-5_1

Duh, QY, \& Grossman, RF (1995). Fatores de crescimento da tireoide, vias de transdução de sinal e oncogenes. As clínicas cirúrgicas da América do Norte , 75 (3), 421-437. https://doi.org/10.1016/s0039-6109(16)46631-4

Fusco, A., Grieco, M., Santoro, M., Berlingieri, MT, Pilotti, S., Pierotti, MA, Della Porta, G., \& Vecchio, G. (1987). Um novo oncogene em carcinomas papilares de tireóide humanos e suas metástases linfonodais. Nature , 328 (6126), 170-172. https://doi.org/10.1038/328170a0

Gerdes AM (2002). Cancergenetic. En oversigt over onkologisk molekylaerbilogi set i relação til det humane genom [Genética do câncer. Uma revisão da biologia molecular oncológica vista em relação ao genoma humano]. Ugeskrift para laeger, 164 (22), 2865-2871.

Carvalho, GA., Graf H. (2005). Anaplastic thyroid carcinoma. Arq Bras Endocrinol Metab, 49 (5).

Haroon Al Rasheed, M. R., \& Xu, B. (2019). Molecular Alterations in Thyroid Carcinoma. Surgical pathology clinics, 12(4), 921-930. https://doi.org/10.1016/j.path.2019.08.002.

Hegedüs L. (2004). Clinical practice. The thyroid nodule. The New England journal of medicine, 351(17), 1764-1771. https://doi.org/10.1056/NEJMcp031436.

Hou, P., Liu, D., Shan, Y., Hu, S., Studeman, K., Condouris, S., Wang, Y., Trink, A., El-Naggar, A. K., Tallini, G., Vasko, V., \& Xing, M. (2007). Genetic alterations and their relationship in the phosphatidylinositol 3-kinase/Akt pathway in thyroid cancer. Clinical cancer research: an official journal of the American Association for Cancer Research, 13(4), 1161-1170. https://doi.org/10.1158/1078-0432.CCR-06-1125

Hou, Y., He, X., \& Chute, D. J. (2020). Paraganglioma-like medullary thyroid carcinoma: A case report and literature review. Diagnostic cytopathology, 48(6), 559-563. https://doi.org/10.1002/dc.24403

Hussain, MR, Baig, M., Mohamoud, HS, Ulhaq, Z., Hoessli, DC, Khogeer, GS, Al-Sayed, RR, \& Al-Aama, JY (2015). Gene BRAF: Dos cânceres humanos às síndromes de desenvolvimento. Revista saudita de ciências biológicas , 22 (4), 359-373. https://doi.org/10.1016/j.sjbs.2014.10.002

Instituto Nacional de Câncer (2022). Câncer de tireoide https://www.inca.gov.br/tipos-de-cancer/cancer-de-tireoide

Kimura ET, Nikiforova MN, Zhu, et al. - High prevalence of BRAF mutations in thyroid cancer: genetic evidence for constitutive activation of the RET/PTCRAS-BRAF signaling pathway in papillary thyroid carcinoma. Cancer Res, 2003, 63(7):1454-1457.

Kimura, ET., Matsuo, S. E., \& Ricarte-Filho, J. C. (2007). TGFbeta, activina e sinalização SMAD em câncer de tiróide [TGFbeta, activin and SMAD signalling in thyroid cancer]. Arquivos brasileiros de endocrinologia e metabologia, 51(5), 683-689. https://doi.org/10.1590/s0004-27302007000500005

Kopnin B. P. (2000). Targets of oncogenes and tumor suppressors: key for understanding basic mechanisms of carcinogenesis. Biochemistry. Biokhimiia, 65(1), $2-27$.

Landa, I., Ibrahimpasic, T., Boucai, L., Sinha, R., Knauf, J. A., Shah, R. H., Dogan, S., Ricarte-Filho, J. C., Krishnamoorthy, G. P., Xu, B., Schultz, N., Berger, M. F., Sander, C., Taylor, B. S., Ghossein, R., Ganly, I., \& Fagin, J. A. (2016). Genomic and transcriptomic hallmarks of poorly differentiated and anaplastic thyroid cancers. The Journal of clinical investigation, 126(3), 1052-1066. https://doi.org/10.1172/JCI85271

Lania, AG, Mantovani, G., \& Spada, A. (2006). Mecanismos da doença: Mutações de proteínas G e receptores acoplados à proteína G em doenças endócrinas. Prática clínica da natureza. Endocrinologia e metabolismo, 2 (12), 681-693. https://doi.org/10.1038/ncpendmet0324

Lee, K., Anastasopoulou, C., Chandran, C., \& Cassaro, S. (2021). Thyroid Cancer. In StatPearls. StatPearls Publishing.

Li, AY, McCusker, MG, Russo, A., Scilla, KA, Gittens, A., Arensmeyer, K., Mehra, R., Adamo, V., \& Rolfo, C. (2019). Fusões RET em tumores sólidos. Revisões de tratamento do câncer, 81, 101911. https://doi.org/10.1016/j.ctrv.2019.101911

Lim, H., Devesa, SS, Sosa, JA, Check, D., \& Kitahara, CM (2017). Tendências na incidência e mortalidade por câncer de tireoide nos Estados Unidos, 19742013. JAMA, 317 (13), 1338-1348. https://doi.org/10.1001/jama.2017.2719

MACIEL RMB. (2002). Molecular Thyroid Tumorigenesis: Implications for The Clinical Practice. Arq Bras Endocrinol Metab, 46 (4); doi.org/10.1590/S000427302002000400009 . 
Lin, PY, Yu, SL e Yang, PC (2010). MicroRNA no câncer de pulmão. Jornal britânico de câncer, 103 (8), 1144-1148. https://doi.org/10.1038/sj.bjc.6605901.

Moura, MM, Cavaco, BM, \& Leite, V. (2015). Proto-oncogene RAS em carcinoma medular de tireoide. Câncer relacionado ao endócrino, 22 (5), R235R252. https://doi.org/10.1530/ERC-15-0070

Nikiforov YE (2008). Carcinoma de tireóide: vias moleculares e alvos terapêuticos. Patologia moderna: um jornal oficial dos Estados Unidos e da Academia Canadense de Patologia, Inc, 21 Suppl 2 (Suppl 2), S37-S43. https://doi.org/10.1038/modpathol.2008.10

Nikiforov, YE, \& Nikiforova, MN (2011). Genética molecular e diagnóstico de câncer de tireóide. Revisões da natureza. Endocrinologia, 7 (10), 569580. https://doi.org/10.1038/nrendo.2011.142

Nikiforova, MN, Wald, AI, Roy, S., Durso, MB, \& Nikiforov, YE (2013). Painel de sequenciamento de próxima geração direcionado (ThyroSeq) para detecção de mutações no câncer de tireoide. O Jornal de endocrinologia clínica e metabolismo, 98 (11), E1852-E1860. https://doi.org/10.1210/jc.2013-2292

Noone, A. M., Cronin, K. A., Altekruse, S. F., Howlader, N., Lewis, D. R., Petkov, V. I., \& Penberthy, L. (2017). Cancer Incidence and Survival Trends by Subtype Using Data from the Surveillance Epidemiology and End Results Program, 1992-2013. Cancer epidemiology, biomarkers \& prevention: a publication of the American Association for Cancer Research, cosponsored by the American Society of Preventive Oncology, 26(4), 632-641. https://doi.org/10.1158/10559965.EPI-16-0520

Okafor, C., Hogan, J., Raygada, M., Thomas, B. J., Akshintala, S., Glod, J. W., \& Del Rivero, J. (2021). Update on Targeted Therapy in Medullary Thyroid Cancer. Frontiers in endocrinology, 12, 708949. https://doi.org/10.3389/fendo.2021.708949

Park, SY, Kim, HI, Kim, JH, Kim, JS, Oh, YL, Kim, SW, Chung, JH, Jang, HW e Kim, TH (2018). Significado prognóstico da extensão extratireoidiana macroscópica invadindo apenas os músculos da alça no carcinoma diferenciado de tireoide. The British Journal of Surgery, 105 (9), 11551162. https://doi.org/10.1002/bjs. 10830

Raman, P., \& Koenig, R. J. (2014). Pax-8-PPAR- $\gamma$ fusion protein in thyroid carcinoma. Nature reviews. Endocrinology, 10(10), 616-623. https://doi.org/10.1038/nrendo.2014.115

Saini, S., Tulla, K., Maker, A. V., Burman, K. D., \& Prabhakar, B. S. (2018). Therapeutic advances in anaplastic thyroid cancer: a current perspective. Molecular cancer, 17(1), 154. https://doi.org/10.1186/s12943-018-0903-0

Shaul, Y. D., \& Seger, R. (2007). The MEK/ERK cascade: from signaling specificity to diverse functions. Biochimica et biophysica acta, 1773(8), 1213-1226. https://doi.org/10.1016/j.bbamcr.2006.10.005

Siegel, R. L., Miller, K. D., \& Jemal, A. (2015). Cancer statistics, 2015. CA: a cancer journal for clinicians, 65(1), 5-29. https://doi.org/10.3322/caac.21254

Staubitz, JI, Schad, A., Springer, E., Rajalingam, K., Lang, H., Roth, W., Hartmann, N., \& Musholt, TJ (2019). Novos rearranjos envolvendo o gene RET em carcinoma papilífero de tireoide. Genética do câncer, 230, 13-20. https://doi.org/10.1016/j.cancergen.2018.11.002

Hoogen, VD., D. J., Meijer, H., Seidl, M. F., \& Govers, F. (2018). The Ancient Link between G-Protein-Coupled Receptors and C-Terminal Phospholipid Kinase Domains. mBio, 9(1), e02119-17. https://doi.org/10.1128/mBio.02119-17

Wells, SA, Jr, Pacini, F., Robinson, BG, \& Santoro, M. (2013). Neoplasia endócrina múltipla tipo 2 e carcinoma medular de tireoide familiar: uma atualização. $O$ Jornal de endocrinologia clínica e metabolismo, 98 (8), 3149-3164. https://doi.org/10.1210/jc.2013-1204

Wiseman, S. M., Loree, T. R., Hicks, W. L., Jr, Rigual, N. R., Winston, J. S., Tan, D., Anderson, G. R., \& Stoler, D. L. (2003). Anaplastic thyroid cancer evolved from papillary carcinoma: demonstration of anaplastic transformation by means of the inter-simple sequence repeat polymerase chain reaction. Archives of otolaryngology--head \& neck surgery, 129(1), 96-100. https://doi.org/10.1001/archotol.129.1.96

Wiseman, S. M., Loree, T. R., Rigual, N. R., Hicks, W. L., Jr, Douglas, W. G., Anderson, G. R., \& Stoler, D. L. (2003). Anaplastic transformation of thyroid cancer: review of clinical, pathologic, and molecular evidence provides new insights into disease biology and future therapy. Head \& neck, 25(8), 662-670. https://doi.org/10.1002/hed.10277

Yi, H. S., Chang, J. Y., Kim, K. S., \& Shong, M. (2017). Oncogenes, mitochondrial metabolism, and quality control in differentiated thyroid cancer. The Korean journal of internal medicine, 32(5), 780-789. https://doi.org/10.3904/kjim.2016.420

Zaballos, M. A., \& Santisteban, P. (2017). Key signaling pathways in thyroid cancer. The Journal of endocrinology, 235(2), R43-R61. https://doi.org/10.1530/JOE-17-0266 